\title{
Projetos pedagógicos dos cursos de licenciaturas e serviço social no contexto REUNI: uma construção coletiva?
}

\author{
Jacqueline Oliveira Lima Zago* \\ Luciene Maria de Souza** \\ Sonia Maria Gomes Lopes***
}

\begin{abstract}
Resumo
Este estudo objetiva apresentar o processo de construção dos Projetos Pedagógicos dos Cursos de Licenciaturas e Bacharelado em Serviço Social da UFTM que foram implementados no contexto do Programa REUNI. Para o desenvolvimento da pesquisa foram analisados documentos oficiais que envolveram as atuais propostas de políticas públicas para a educação superior, especificamente o Programa REUNI, bem como dados empíricos da instituição pesquisada. Se, por um lado, é necessário reconhecer o avanço do trabalho coletivo e espaço de formação pedagógica na construção dos projetos pedagógicos dos cursos de Licenciaturas e Serviço Social, por outro, a pesquisa constatou que a concretização da proposta de implantação de currículo inovador nesses cursos encontrou diversas limitações impostas pelo Programa REUNI.
\end{abstract}

Palavras-chave: REUNI; UFTM; Projetos pedagógicos.

\section{Educational projects of undergraduate courses and social services REUNI in context: a collective construction?}

\begin{abstract}
This study aims to present the process of construction of Educational Projects and Undergraduate Courses Bachelor of Social Service UFTM that were implemented in the context of the Programme REUNI. For the development of the survey official documents were analyzed surrounding the current public policy proposals for higher education, specifically the Program REUNI, as well as empirical data from the research institution. On one hand, it is necessary to recognize the advancement of collective work space and teacher training in the construction of educational projects and the courses Undergraduate Social Work, on the other hand, the survey found that the completion of the proposed deployment of innovative curriculum in these courses found several limitations imposed by the Program REUNI.
\end{abstract}

Keywords: REUNI, UFTM, Educational projects

\section{Introdução}

O presente texto objetiva apresentar o processo de construção dos Projetos Pedagógicos dos Cursos de Licenciaturas em Ciências Biológicas, Química, Física, Matemática, História e Geografia e do Curso de Bacharelado em Serviço Social da Universidade Federal do Triângulo Mineiro que foram implantados no contexto do Programa de Apoio a Planos de Reestruturação e Expansão das Universidades Federais - REUNI. O intuito é promover uma discussão no sentido de apontar as limitações, desafios e avanços na construção coletiva dos PPCs diante desse cenário.

Desde que foi transformada em Universidade no ano de 2005, a UFTM tem passado por um expressivo processo de expansão quantitativa e de qualidade no seu trabalho. De instituição consolidada na área da saúde onde

\footnotetext{
* Endereço eletrônico: jacqueline.o.l.zago@ gmail.com

** Endereço eletrônico: lucienesociais@yahoo.com.br

*** Endereço eletrônico: nude@ proens.uftm.edu.br
}

oferecia três cursos de graduação (Medicina, Enfermagem e Biomedicina) expandiu a sua oferta e passou a conviver com novas áreas do conhecimento: Letras, Psicologia, Fisioterapia, Terapia Ocupacional e Educação Física, o que contribuiu para a sua reconfiguração social perante a comunidade onde está inserida.

Em 2007 a jovem Universidade foi convidada a aderir ao Programa de Apoio a Planos de Reestruturação e Expansão das Universidades Federais - REUNI como oportunidade de consolidar seu processo de transformação em Universidade. Esse programa estava entre as metas do governo Lula para expansão do Ensino Superior e estava articulado com o Programa Universidade para Todos - PROUNI, na tentativa de combater o baixo contingente de alunos de 18 a 24 anos que frequenta o ensino superior, sobretudo os provenientes de escolas públicas, para as etnias sub-representadas 
nas universidades (negros e índios) e para os jovens pertencentes às camadas sociais mais empobrecidas. (OLIVEIRA, et al, 2006)

Em reunião com o órgão consultivo e deliberativo pleno, na ocasião chamado de Congregação, o então Reitor Pró-Tempore em exercício convidou a comunidade acadêmica a estudar a proposta do governo. É preciso observar que a instituição teria uma autonomia relativa, tendo em vista a contrapartida financeira que viria com o programa, sendo a oportunidade de restaurar física e ideologicamente a universidade. Foi assim que em uma nova reunião no dia 25 de outubro daquele mesmo ano foi aprovado um compromisso com as metas do REUNI. Aprovou-se, ressalte-se ainda, uma expansão de vagas no Ensino Superior, nos moldes e prerrogativas das diretrizes do Programa REUNI, tais como: a redução das taxas de evasão; ocupação de vagas ociosas e aumento de vagas de ingresso, especialmente no período noturno; revisão da estrutura acadêmica, com reorganização dos cursos de graduação e atualização de metodologias de ensino-aprendizagem, buscando a constante elevação da qualidade e diversificação das modalidades de graduação, preferencialmente não voltadas à profissionalização precoce. Essas prerrogativas seriam o cenário que o ensino superior público estava enfrentando em seu modelo e conteúdo de universidade iluminista para se reestruturar em bases gerenciais.

Diante disso, a Pró-Reitoria de Planejamento da UFTM constituiu uma Comissão para elaboração do Plano REUNI-UFTM em conjunto com a Pró-Reitoria de Ensino via Divisão de Apoio Técnico Pedagógico - DATP, a PróReitoria de Pesquisa e Pós-Graduação e órgãos diretos da administração central. Essa comissão elaborou, aprovou nos órgãos pertinentes e encaminhou para o MEC a proposta para reestruturação e expansão da UFTM para o período de 2009 a 2012. O projeto contemplou a criação dos cursos noturnos de Licenciaturas e Serviço Social e cursos de Engenharias, diurnos, além de uma ampla revisão curricular e de processo de avaliação dos cursos já ofertados.

Para os cursos de licenciatura a serem implantados, os projetos de organização acadêmico-curricular em fase de construção propõem uma estrutura flexível, interdisciplinar, requisitos de qualidade, a fim de promover a formação dos cidadãos com sólidas bases humanísticas, culturais, científicas e profissionais. Os currículos propostos possibilitarão a criação de ciclos básicos por área de formação, que resultará no aumento de vagas, na possibilidade de mobilidade estudantil dentro e fora da Universidade e novas formas de acesso, favorecendo a inclusão social e estudantil. A maioria dos docentes envolvidos na criação desses cursos tem participado ativamente do processo, propondo modernização $e$ inovação das técnicas de ensino $e$ exercendo o seu papel de facilitador, orientador e harmonizador do "aprender fazendo" e "aprender a aprender", condições fundamentais para que o discente tenha uma visão crítica e participativa, dentro do seu próprio processo de capacitação profissional, que não termina com a condição de egresso (UFTM, 2007, p. 15).

Para o acompanhamento do REUNI-UFTM foi criada a Coordenação do REUNI e, junto com esta coordenação, a Divisão de Apoio Técnico Pedagógico-DATP teve papel fundamental no sentido de subsidiar os projetos dos novos cursos. Um grupo foi constituído em formato de comissão, nomeado pela Reitoria, para elaboração de uma proposta curricular inovadora, especialmente para os cursos de Licenciaturas e Serviço Social. Esse grupo, coordenado pela DATP, foi composto por servidores técnicos e docentes da UFTM e convidados da comunidade externa. A ele foi dada a tarefa de construir projetos que superassem a fragmentação da formação de docentes para a educação básica e a profissionalização precoce, priorizando a formação generalista e humanística, em atendimento às diretrizes do Projeto REUNI, bem como estudos desenvolvidos pela Universidade Federal da Bahia e experiências desenvolvidas na USP Leste na Escola de Artes, Ciências e Humanidades. A partir desse trabalho realizado ao longo de 2008 foi elaborada uma proposta curricular inovadora denominada de Ciclo Comum de Formação para os cursos de Licenciaturas e Bacharelado em Serviço Social, conforme publica o próprio grupo que submeteu o projeto:

A concepção curricular assumida pelo grupo procurou atender a duas perspectivas básicas: a necessidade de uma formação generalista e humanística, que concorresse 
para uma relação crítica-reflexiva entre sujeito e mundo social e também a necessidade de formar profissionais competentes nos conhecimentos específicos da sua área de saber. Para tal, pensou-se ser fundamental ter a proposta curricular alicerçada nos seguintes princípios: flexibilidade curricular; metodologias de ensino que tivessem como foco a aprendizagem; interdisciplinaridade; postura crítico-reflexiva acerca das discussões do mundo contemporâneo; indissociabilidade entre teoria e prática e base humanística, cultural, científica $e$ profissional (PRATA-LINHARES et al., 2008).

Percebe-se que a perspectiva do grupo responsável pela construção da proposta era de atender uma perspectiva de um currículo em rede, de uma formação mais completa no sentido da integralidade da pessoa humana. $\mathrm{O}$ grupo interdisciplinar pontuou seu trabalho como um processo de formação continuada, assim como o currículo ora proposto. Em momento algum o grupo apresentou uma proposta fechada, acima de críticas, mas ao contrário, uma construção repleta de rupturas e mudanças, baseando-se nos estudos de Paulo Freire, Ivani Fazenda, Ilma Veiga, Sacristán, entre vários outros teóricos do currículo.

Outro ponto inovador nessa proposta foi a inserção da mobilidade estudantil, que oportuniza ao aluno fazer uma reopção de curso, entre as Licenciaturas e Serviço Social, ao final do primeiro ano, caso ele não tenha se identificado com a primeira escolha. (UFTM, 2009). O currículo foi organizado em Eixos Temáticos que, por sua vez, se desdobrariam em Unidades Temáticas, numa tentativa de superação da fragmentação disciplinar. Os eixos temáticos são: Vida em Sociedade e Formação Pedagógica Comum, Múltiplas Linguagens e Especificidades da área de Formação. Trata-se de um currículo em rede, assim como a concepção de conhecimento adotada pela equipe de elaboração dos projetos. Para organizar essa proposta foi criada uma coordenação que, entre outros, seria responsável por articular os diferentes cursos de Licenciaturas e o curso de Serviço Social dentro dessa perspectiva comum, desde o planejamento como oferta e organização de turmas, reuniões deliberativas até a avaliação.

A proposta do Ciclo Comum de Formação trouxe em seu bojo o princípio do trabalho coletivo e para isso os docentes envolvidos foram instigados a questionar sua própria formação e atuação. Como bem salienta Veiga (2003), construir uma proposta que conte com a participação dos atores sociais envolvidos numa perspectiva de gestão democrática é fundamental para a identidade do grupo com o projeto, já que este,

(...) é um meio de engajamento coletivo para integrar ações dispersas, criar sinergias no sentido de buscar soluções alternativas para diferentes momentos do trabalho pedagógico - administrativo, desenvolver o sentimento de pertença, mobilizar os protagonistas para a explicitação de objetivos comuns definindo o norte das ações a serem desencadeadas, fortalecer a construção de uma coerência comum, mas indispensável para que a ação coletiva produza seus efeitos (VEIGA, 2003, p.277).

\section{A contribuição da DATP na implantação do ciclo comum de formação}

A Divisão de Apoio Técnico Pedagógico, criada em 1993, nasceu com o objetivo de promover ações para a melhoria do processo de ensino aprendizagem na instituição e, dentre as suas principais atribuições, destacam-se: o trabalho de construção, acompanhamento e avaliação dos projetos pedagógicos dos cursos, dos planos de ensino dos componentes curriculares e a oferta de cursos e eventos de formação pedagógica aos docentes. A DATP teve sua nomenclatura alterada em 2011 para Núcleo de Desenvolvimento Educacional, porém manteve as mesmas atribuições.

A equipe da DATP é formada por Assistentes Administrativos, Pedagogos e Técnicos em Assuntos Educacionais, todos especialistas com mestrado e/ou doutorado e tem como responsabilidade prestar assessoria aos Núcleos Docentes Estruturantes-NDEs e coordenadores dos cursos na elaboração dos Projetos Pedagógicos dos Cursos de Graduação-PPCs oferecidos pela UFTM. Esta equipe exerce um papel de Câmara Técnica junto ao Conselho de Ensino, onde submete um parecer, que, embasado na legislação vigente, no Projeto Pedagógico Institucional e nas regulamentações institucionais, subsidia o processo de aprovação pelo colegiado. Assessora ainda na abertura de processo de Reconhecimento e 
Renovação de Reconhecimento dos Cursos de Graduação e de Credenciamento no órgão de regulação Inep/MEC dentre outras atividades relacionadas ao ensino de graduação.

$\mathrm{Na}$ implantação dos novos cursos coube à DATP o papel de coordenar os trabalhos de construção dos Projetos Pedagógicos implantados na instituição via REUNI juntamente com as pessoas convidadas para este fim. Conforme já abordado anteriormente, após um período de muitos estudos, bem como conhecimento de experiências de outras universidades, optou-se por adotar um modelo de currículo para os cursos de Licenciaturas e Serviço Social que foi denominado de Ciclo Comum de Formação.

Além disso, a elaboração do Projeto Pedagógico permitiu a construção da identidade da nova instituição e também fez com que o próprio grupo que participara da elaboração da proposta se identificasse com o trabalho realizado. Para Veiga (1995), um ensino de qualidade só é possível quando a comunidade tem claros os caminhos a serem percorridos. Esse acompanhamento visa romper com a separação entre concepção e execução, entre o pensar e o fazer, entre teoria e prática. Busca resgatar o controle do processo e do produto do trabalho pelos educadores. Em outras palavras, quando não há participação logo não há envolvimento e sentimento de pertença.

A coordenação desse trabalho pela DATP trouxe a reflexão da prática pedagógica para a sala de aula, para as práticas consagradas nas ciências médicas e da saúde, no intuito de rever as metodologias de ensino e concepção de avaliação utilizada com vistas a um novo currículo, uma nova avaliação e um novo perfil de docente que, nessa perspectiva, concilia tanto o conhecimento específico de sua área de atuação quanto o domínio dos saberes pedagógicos, bem como a consciência de seu papel como sujeito social, responsável também pela construção de sua experiência. Por isso, o Projeto Pedagógico construído concebeu também um perfil de professor que atuaria nessa proposta e, por isso, os processos concurso para docentes tiveram como base as orientações desse Projeto Pedagógico.

\section{A materialização da proposta}

Se, por um lado, a experiência inicial de construção coletiva dos projetos pedagógicos dos cursos de Licenciaturas e Serviço Social da UFTM propiciou um aprendizado dos sujeitos envolvidos no processo, por outro, as condições materiais para consolidar a nova configuração curricular apresentou cotidianamente diversas limitações. Mesmo que no documento oficial estivesse o compromisso de que

"A expansão da UFTM ocorrerá de forma responsável e transparente. Uma nova vaga ou novo curso somente serão criados quando as condições materiais $e$ de recursos humanos estiverem plenamente satisfeitas. Esse é o nosso compromisso com a comunidade UFTM" (UFTM, 2007, p. 4).

$\mathrm{Na}$ prática, isso não foi possível. Nem todos os atores sociais que participaram do processo de elaboração da proposta estiveram presentes quando da implantação da mesma, a assessoria contratada não foi incorporada à equipe, e a chegada de novos docentes, à medida que vagas eram liberadas, contribuíram para o desmantelamento do projeto original. Além disso, na posse da nova chefe do executivo os concursos foram suspensos e uma nova categoria profissional de docente passou a conviver no cenário institucional: os professores temporários. Todo esse cenário gerou uma intensa precarização das condições de trabalho principalmente dos docentes envolvidos na primeira etapa do ciclo comum de formação, o que tem provocado críticas e resistências na continuidade dessa proposta.

A configuração curricular na proposta do Ciclo Comum de Formação para os cursos de Licenciaturas e Serviço Social, que previa como fundamentos essenciais a flexibilidade curricular, metodologias de ensino com foco na aprendizagem, a interdisciplinaridade, dentre outros princípios, desconfigurou-se em função das limitações relacionadas à própria formação inicial dos professores, mas principalmente em virtude das dificuldades enfrentadas pelas precárias condições de trabalho e infraestrutura impostas pelo Programa REUNI.

Vale lembrar que o REUNI foi um projeto amplamente divulgado como um instrumento que, respeitada a autonomia universitária, poderia viabilizar uma reestruturação de grande alcance do parque universitário federal. $\mathrm{O}$ documento afirmou que as instituições que aderissem ao programa teriam as verbas de custeio integralmente recuperadas, os concursos públicos seriam retomados, ao mesmo tempo em que se restabeleceria a capacidade de investimento das 
instituições de forma a sustentar a expansão e a interiorização do ensino superior público, com dez novas universidades públicas federais e 48 novos campi universitários. (BRASIL, 2007).

Para tanto, após cinco anos desde a sua concepção enquanto ação do Governo Federal, o REUNI está sendo entendido numa perspectiva crítica como a materialização de orientações expressas do Banco Mundial que vem dando a direção ideológica para a expansão do capital, colocando a educação para o alívio da pobreza, não só para o Brasil, mas para todos os países em ajustamento à política econômica mundial e ao papel dependente exercido por nações em desenvolvimento (LIMA, 2010). Nas diretrizes do Programa, palavras como realocação, redimensionamento, racionalização são recorrentes. Está explícita desde o projeto original uma crítica ao modelo tradicional de universidade, voltado quase que exclusivamente para a pesquisa, para um modelo mais voltado à formação em nível de graduação, voltado quase exclusivamente para o ensino, uma "universidade operacional". (CHAUÍ, 1999). Assim, a universidade

capitalista, excludente e seletiva. Se, por um lado, apresentam discursos democráticos e includentes, defendendo a democratização do acesso à escola; por outro, organizam-se sistemas duais de ensino: uma escola propedêutica para a elite - que garante o acesso dos alunos ao conhecimento científico e, portanto, o alcance dos cursos de graduação mais concorridos e que assegurem maior status social; e uma escola técnico profissionalizante para a maioria que pertence à classe menos abastada, com possibilidade de acesso aos cursos de graduação de menor status social, dentre estes, os cursos de Licenciatura, que formam professores (BORGES, 2010, p.48-49).

As diretrizes do REUNI invocam o critério para abertura de novas turmas em novos cursos com um número elevado de alunos e número reduzido de professores e técnicos administrativos. A UFTM materializa essa lógica nos projetos em andamento dos cursos de Engenharia e das Licenciaturas e Serviço Social. Enquanto para os primeiros foram previstos investimentos tais como um novo campi, os segundos tiveram que se adaptar à estrutura existente dos cursos da área de saúde. Essa diferenciação, no entanto, resume-se a espaço físico, porque tanto uma área como a outra, convive com a dificuldade de falta de professores e técnicos para a implementação de fato de sua proposta pedagógica.

Para demonstrar este triste cenário, apresentamos a seguir tabela com dados da expansão da UFTM no período de 2004 a 2011.

Tabela 1

EXPANSÃO QUANTITATIVA DA UFTM - 2004/2011

\begin{tabular}{|c|c|c|c|c|c|c|c|c|c|c|}
\hline \multirow[t]{2}{*}{ ANOS } & \multicolumn{2}{|c|}{\begin{tabular}{|c|} 
CURSOS \\
PROFIS. PÓS- \\
MÉDIO \\
\end{tabular}} & \multicolumn{2}{|c|}{$\begin{array}{c}\text { GRADUAÇÃ } \\
\text { O }\end{array}$} & \multicolumn{2}{|c|}{\begin{tabular}{|c|} 
PÓS- \\
GRADUAÇÃ \\
$\mathbf{O}$ \\
\end{tabular}} & \multicolumn{2}{|c|}{\begin{tabular}{|c|} 
TÉCNICOS \\
ADMINISTRATIVO \\
S
\end{tabular}} & \multicolumn{2}{|c|}{ DOCENTES } \\
\hline & $\begin{array}{c}\mathbf{N}^{\circ} \\
\text { cursos }\end{array}$ & Alunos & $\begin{array}{c}\mathrm{N}^{\circ} \\
\text { cursos }\end{array}$ & Alunos & $\begin{array}{c}\mathbf{N}^{\circ} \\
\text { cursos }\end{array}$ & Alunos & Estatutário & CLT & Estatutário & $\begin{array}{c}\text { Substitutos/ } \\
\text { Temporári } \\
\text { os }\end{array}$ \\
\hline 2004 & 5 & 191 & 3 & 730 & 2 & 100 & 268 & 0 & 136 & 45 \\
\hline 2005 & 5 & 183 & 3 & 729 & 2 & 111 & 282 & 234 & 133 & 54 \\
\hline 2006 & 6 & 199 & 8 & 813 & 2 & 116 & 303 & 62 & 191 & 39 \\
\hline 2007 & 6 & 267 & 8 & 1002 & 2 & 115 & 308 & 62 & 189 & 44 \\
\hline 2008 & 6 & 224 & 9 & 1.191 & 4 & 169 & 392 & 73 & 204 & 50 \\
\hline 2009 & 8 & 419 & 17 & 1.971 & 4 & 149 & 414 & 46 & 283 & 56 \\
\hline 2010 & 9 & 449 & 24 & 3.001 & 6 & 201 & 483 & 41 & 398 & 26 \\
\hline 2011 & 10 & 612 & 24 & 3.922 & 9 & 588 & 461 & 46 & 406 & 103 \\
\hline
\end{tabular}

Fonte: PROPLAN-UFTM, 2012.

Em relação aos dados apresentados na tabela, observa-se que, embora o número de alunos tenha mais que quadruplicado, o mesmo não aconteceu com os docentes, já que a proporção de aluno por professor foi dobrado. Isso é a materialização de políticas de expansão que 
almejam transformar a instituição universidade em bases empresariais, numa relação custo-benefício. A prerrogativa imposta pelas políticas públicas educacionais é fazer mais com menos, flexibilizar processos, desburocratizar fluxos, não no sentido de melhorar as condições de trabalho, mas extrair mais sobretrabalho no exercício.

Dessa maneira, as universidades federais, ainda que públicas, passam agora a ser "expandidas" e "reestruturadas" trazendo para o seu interior o cerne das lutas sociais, com formação para as elites nos cursos tradicionais ofertados preferencialmente no diurno e, para "aqueles-quevivem-do-trabalho" (ANTUNES, 1995), cursos menos dispendiosos para a máquina pública administrativa, a exemplo dos cursos de Licenciaturas.

No caso específico dos cursos de Licenciatura da UFTM, ou seja, para professores universitários formadores de professores para a educação básica, é lançado o desafio de problematizar a educação no contexto da reestruturação produtiva e novas nuances do capitalismo mundializado. Essa tarefa se torna mais urgente e necessária, e, embora especificidades precisem ser resguardadas, a educação é uma só e tem um papel fundamental. Não será capaz de, conforme alertou Mészáros (2005), transformar sozinha a sociedade em seu projeto de emancipação. A universalização da educação deverá ocorrer com a universalização do trabalho. Por isso, essas ditas reformas são insuficientes, limitadas e muitas vezes paliativas. Não objetivam atacar o problema estrutural que atinge a sociedade.

\section{Algumas Considerações}

Apesar do clima favorável à emergência de projetos pedagógicos inovadores fomentados pelas políticas públicas educacionais, os resultados decorridos após quase quatro anos de existência dos Cursos de Licenciaturas e Serviço Social não são muito animadores. As tentativas de implantar uma formação geral, humanística e interdisciplinar propiciada pela estruturação dos currículos em Eixos e Unidades Temáticas de modo geral, não alcançaram o objetivo inicial do grupo que idealizou a proposta.

Respondendo à problematização indicativa deste artigo, a construção dos Projetos Pedagógicos dos Cursos de Licenciatura e Serviço Social da UFTM deu-se numa perspectiva coletiva, mas essa perspectiva perdeu-se quando da materialização da proposta.

O cenário descrito ao longo do texto denuncia uma grande contradição na implantação do Ciclo Comum de Formação e no cumprimento das metas REUNI-UFTM. Se, por um lado, foi pactuada dentre as metas ${ }^{1}$ uma proposta curricular inovadora de formação dos discentes dos cursos de Licenciaturas e Serviço Social, por outro lado, foram também as limitações apresentadas na concretização desse mesmo Programa que provocaram uma profunda crise de identidade do Ciclo Comum de Formação.

Outro ponto importante a ser ressaltado é que os projetos pedagógicos dos cursos de Licenciaturas e Serviço Social da UFTM sofreram ao longo desse período inúmeras transformações substanciais. Todas essas mudanças refletiram significativamente no conceito de Ciclo Comum adotado inicialmente ${ }^{2}$. O sistema de gestão acadêmica não conseguiu incorporar a questão da flexibilidade curricular como a formação de turmas mistas de alunos e a gestão compartilhada das Unidades Temáticas ministradas por mais de um docente. Essas dificuldades, principalmente a falta de um arcabouço legal interno que regulamentasse essas questões, foram ao longo do tempo desmotivando o trabalho coletivo e o retorno à perspectiva unilateral de formação, ou seja, um currículo disciplinar.

$\mathrm{O}$ projeto piloto não conseguiu ser consolidado na sua integralidade porque o movimento de implantação dos novos currículos não caminhou na mesma velocidade do sistema de gestão acadêmica, pois o Regimento Geral da UFTM ainda estava sendo apreciado e não se tinha um Regulamento de Graduação que privilegiasse os princípios de interdisciplinaridade, flexibilidade e autonomia do aluno.

Em virtude dessa conjuntura, pensar a formação pedagógica e continuada dos docentes neste cenário é um desafio que se apresenta. Embora prevista em forma de metas nos documentos oficiais, não se cria uma dotação orçamentária específica para esse fim. Para minimamente atender à demanda, a DATP lança mão de projetos esporádicos, tendo em vista que ainda não foi implantado na universidade um programa institucional de formação docente. O fazer pedagógico no ensino superior tem sido muitas vezes subjugado a segundo plano em virtudes de demandas urgentes e que regulam a oferta de educação superior. Um exemplo disso é o surgimento de uma nova categoria de vínculo à 
instituição: os professores temporários. Esses profissionais assinam um contrato de trabalho com prazo determinado de até dois anos, o que fragiliza o andamento das atividades nos cursos envolvidos, fragmenta a consciência de pertencimento de classe da categoria e dificulta o desenvolvimento do trabalho coletivo no processo como um todo. Sem contar que este tipo de trabalho tem atraído cada vez menos candidatos, conforme demonstra a republicação de editais pelas IFES.

A experiência do Ciclo Comum de Formação na UFTM nos permite constatar avanços e desafios que emergem na concretização da proposta. Os avanços dizem respeito à construção coletiva baseada em uma perspectiva diferenciada de formação de profissionais. Já os desafios se relacionam às limitações do próprio programa REUNI no que concerne à mínima destinação de recursos orçamentários, previsão de força de trabalho e condições infraestruturais de maneira geral. Pesquisas recentes sobre os reflexos do REUNI nas diferentes instituições federais de ensino superior têm apontado de modo geral um quadro desalentador. Os docentes estão sobrecarregados de aulas na graduação, com pouco tempo para dedicar às pesquisas e atividades de extensão, cobranças internas e externas para aumento da produção científica, o que tem resultado em constante adoecimento dos professores. (LIMA, 2007; SGUISSARDI e SILVA JÚNIOR, 2009).

Por fim, é importante ressaltar que a discussão da temática apresentada não foi esgotada, uma vez que esta análise é apenas parte de um processo de investigação mais amplo que se encontra em andamento. Para tanto, o intuito do estudo foi apresentar, ainda que brevemente, uma análise do cenário de como as políticas públicas educacionais, especialmente o REUNI, tem impactado o fazer pedagógico nas instituições federais de ensino superior. Nesse sentido, socializar a experiência vivenciada pela UFTM nos leva a refletir sobre qual concepção de Universidade está implícita no Programa REUNI e como os impactos dessas escolhas - que não são "neutras" têm recaído e provocado consequências na qualidade do ensino ofertado no país, bem como nas condições de trabalho dos sujeitos envolvidos nesse processo.

\section{Notas}

1 Uma das dimensões do Plano REUNI-UFTM foi o compromisso da Reestruturação Acadêmico-
Curricular. (UFTM, 2007).

2 Ocorreu a divisão do que seria um único Instituto de Educação em dois Institutos, um voltado para a Ciências Humanas e Sociais e outro para Ciências Exatas e Naturais o que resultou na fragmentação das áreas de conhecimento dificultando ainda mais a desafiadora tarefa do trabalho coletivo.

\section{Referências Bibliográficas}

ALMEIDA FILHO, Naomar de. Universidade Nova: textos críticos e esperançosos. Brasília, DF: Editora Universidade de Brasília; Salvador: EDUFBA, 2007.

ANASTASIOU, Lea das Graças C.; PIMENTA, Selma G. Docência no ensino superior. São Paulo: Cortez. 2005.

ANTUNES, R. O Caracol e sua concha. São Paulo: Boitempo, 2005.

Cortez, 2011.

O continente do labor. São Paulo:

BORGES, M.C. A formação de professores nos projetos de expansão das Universidades Públicas Federais do Triângulo Mineiro: uma análise dos discursos, das políticas e das práticas. 2011. 128 p. Relatório de pesquisa (Pós-doutorado em Educação). Faculdade de Educação. Universidade de São Paulo, São Paulo, 2011.

BRASIL. REUNI - Reestruturação e Expansão das Universidades Federais, Brasília, 2007.

CAMINI, Lucia. A política educacional do PDE e do Plano de Metas Compromisso Todos pela Educação. Revista Brasileira de Política e Administração da Educação. Porto Alegre: ANPAE, v. 26, n.3, p. 535-564, 2010.

CHAUÍ, Marilena. A universidade operacional. Revista Adunicamp - desafios da universidade pública. Associação de Docentes da Unicamp, ano 01, n. 01, jun. 1999, p. 06-09.

CUNHA, Maria Isabel da. Docência na universidade, cultura e avaliação institucional: saberes silenciados em questão. Revista Brasileira de Educação. Rio de Janeiro. ANPED, v.11. n. 32, 
p. $258-271,2006$.

FRANÇA, P. I. S. de. As Reformas no Setor Educacional Brasileiro e a Expansão do Ensino Superior. In: FRANÇA, R. L. (Orgs). Educação e Trabalho: políticas públicas e a formação para o trabalho. Campinas, SP: Editora Alínea, 2010.

MÉSZÁROS, István. Educação para além do Capital. Editora: Boitempo, 2005.

LIMA, Antonio Bosco de. Estado, Educação e Controle Social. In: FRANÇA, Robson Luiz de. Educação e Trabalho: políticas públicas e a formação para o trabalho. Campinas, SP: Alínea, 2010, p. 11-30.

LIMA, Katia. Contra-reforma na Educação Superior: de FHC a Lula.São Paulo, Xamã, 2007.

OLIVEIRA, João F.; CATANI, Afrânio M. et al. Democratização do acesso e inclusão na educação superior no Brasil. Brasília: MEC/INEP, 2006.

SGUISSARDI, Valdemar. Universidade brasileira no século XXI. São Paulo: Cortez, 2009.

SGUISSARDI, Valdemar.; SILVA JÚNIOR, J. R. Trabalho intensificado nas federais: pós graduação e produtivismo acadêmico. São Paulo: Xamã, 2009.

UNIVERSIDADE FEDERAL DO TRIÂNGULO MINEIRO. Projetos Pedagógicos dos Cursos de Licenciaturas e Serviço Social. Uberaba, 2009.

UNIVERSIDADE FEDERAL DO TRIÂNGULO MINEIRO. Plano de Reestruturação e Expansão da Universidade Federal do Triângulo Mineiro UFTM. Uberaba, 2007.

UNIVERSIDADE FEDERAL DO TRIÂNGULO MINEIRO. Projeto Pedagógico Institucional. Uberaba, 2009.

VEIGA, Ilma Passos A. Inovações e Projeto Político - Pedagógico: uma relação regulatória ou emancipatória? In: Caderno Cedes, Campinas, V.23, n.61, p.267 - 281, dezembro 2003. Disponível em www.cedes.unicamp.br.

VEIGA, Ilma Passos A. (Org). Projeto Político Pedagógico da escola: uma construção possível. Campinas, SP: Papirus, 1995.

VEIGA, Ilma Passos A. (Org). Escola: espaço do Projeto Político - Pedagógico. Campinas, SP: Papirus, 1998.

Sobre as autoras:

Jacqueline Oliveira Lima Zago: Pedagoga/UFTM; Mestranda em Educação/UFU, Uberaba.

Luciene Maria de Souza: Técnica em Assuntos Educacionais/UFTM; Doutora em Educação/UFU, Uberaba.

Sonia Maria Gomes Lopes: Pedagoga UFTM, Uberaba.

Recebido em: 10/2012

Aprovado em: 06/2013 